\title{
Periodontal Disease and Associated Factors in Patients with Rheumatoid Arthritis
}

\author{
Sena Tolu ${ }^{1}$, Delal Öztürk², Ahmet Üşen ${ }^{1}$, (i) Aylin Rezvani ${ }^{1}$, (i) Tuba Develi ${ }^{3}$ \\ ${ }^{1}$ Department of Physical Medicine and Rehabilitation, Medipol University Faculty of Medicine, Istanbul, Turkey \\ ${ }^{2}$ Department of Physical Medicine and Rehabilitation, Bezmialem Vakıf University Faculty of Medicine, Istanbul, Turkey \\ ${ }^{3}$ Department of Oral and Maxillofacial Surgery, Medipol University Faculty of Dentistry, Istanbul, Turkey
}

\begin{abstract}
Introduction: Periodontitis (PD) and rheumatoid arthritis (RA) are chronic inflammatory diseases that share complex multifactorial pathologic processes, including genetics, environmental and inflammatory factors. This study aims to evaluate the periodontal status and its association with sociodemographic and clinical factors in patients with RA.

Methods: This study included 51 patients with RA; the mean age was $49.75 \pm 9.79$ years old and $10.59 \pm 6.37$ years of disease duration. Sociodemographic data and the rheumatologic assessment included detailed profiling of the disease and serology were noted. A full mouth periodontal examination, including the Gingival index, Plaque index, Pocket probing depth and clinical attachment level, was carried out by a periodontist. The periodontal status was classified according to the Centers for Disease Control-American Academy of Periodontology clinical case definitions.

Results: Forty-five patients (88.2\%) were female. 37.3\% of patients had DAS28>3.2. All patients had PD, in mild (54.9\%) to moderate (45.1\%) severity. Aging, impaired oral hygiene, smoking, secondary Sjögren's syndrome and high disease activity were associated with moderate PD.

Discussion and Conclusion: This study results identified a serious need to pay particular attention to oral health in patients with RA and refer these patients for periodontal evaluation and treatment. Future studies are needed to better investigate whether if efforts to prevent periodontal disease may also help prevent RA.

Keywords: Periodontitis; rheumatoid arthritis; risk factor.
\end{abstract}

$\mathrm{R}_{\mathrm{t}}^{\mathrm{h}}$ heumatoid arthritis (RA) is a progressive, systemic autoimmune disease characterized by synovitis and leads to joint destruction, progressive disability and diminished patient's quality of life ${ }^{[1]}$. RA is a public health worldwide problem resulting in high economic costs and social impact ${ }^{[2]}$. Temporomandibular joint disorders, secondary Sjögren's syndrome (sSS), periodontal and dental disease are the most common orofacial manifestations in patients with $\mathrm{RA}^{[3]}$. Patients with RA had been reported significantly more periodontal disease compared with healthy individuals in previous studies. Over the past years, the association between periodontitis (PD) and RA has received considerable increasing attention ${ }^{[4-8]}$.

PD is a chronic infectious inflammatory disease leading to the destruction of the attachment of the periodontal ligament and the loss of supporting alveolar bone. Eventually, the loss of periodontal support tissues may cause the loss of teeth affected ${ }^{[4,5]}$. Periodontal diseases were reported

Correspondence (iletişim): Sena Tolu, M.D. Medipol Universitesi Tip Fakultesi, Fiziksel Tip ve Rehabilitasyon Anabilim Dali, Istanbul, Turkey Phone (Telefon): +90 5054424722 E-mail (E-posta): dr.sena2005@gmail.com 
with the prevalence of mild PD being $35 \%$ and moderate to severe PD as $11 \%$ in 2010, affecting 3.9 billion people ${ }^{[9]}$. As the world's population is aging, PD has become an important public health problem that causes a burden on the healthcare system ${ }^{[10]}$. The potential influence of periodontal pathogens and PD on initiation and/or progression of several systemic diseases, such as malignancy, type 2 diabetes mellitus (DM), cardiovascular and respiratory diseases, adverse pregnancy outcomes and neurodegenerative disease, has been postulated ${ }^{[11-13]}$. The possible mechanisms involving the modulations of an inflammatory pathway and systemic immunity are associated with a bacterial challenge and represent a portal of entry for periodontal pathogens, bacterial endotoxins, and pro-inflammatory cytokines ${ }^{[11]}$.

In a systematic review, PD has been confounded as a factor in the initiation and maintenance of the autoimmune inflammatory responses that occur in RA and also reported as an important factor for increased disease activity and refractoriness ${ }^{[14]}$. RA and PD share similar genetic and environmental risk factors, such as expression of the MHC class II HLA-DRB1 allele and smoking. Besides, the destructive mechanisms that drive chronic bone erosion in RA and chronic gum destruction in PD are similar in both diseases ${ }^{[4,5]}$. The recent evidence has showed that PD and RA are closely linked and share elements regarding pathogenic mechanisms ${ }^{[6-8]}$. Colonization of bacterial complex in dental plaque induces chronic periodontal inflammation ${ }^{[6,7]}$. Gram-negative anaerobic bacteria, such as Porphyromonas gingivalis and Aggregatibacter actinomycetemcomitans in the dental plaque biofilm, are commonly known peri-ᄀodontal pathogens involved in RA pathogenesis by creating a pro-inflammatory environment and inducing citrullinated autoantigens targeted by anticitrullinated protein antibodies (ACPA $)^{[7]}$. The association between the concentration of circulating antibodies to Porphyromonas gingivalis and expression ACPA has been demonstrated $^{[8]}$.

The results from population-based studies on the potential association between PD and RA are inconsistent ${ }^{[15-17]}$. This discrepancy may depend on variables in different ethnic groups, small numbers of subjects with RA and/or the lack of uniformity in the definition of PD. In Turkey, the prevalence of RA adjusted for the general population aged 16 or over was estimated at $0.56 \%{ }^{[18]}$. Currently, we lack detailed examination data about the oral health of patients with RA. Ay et al., ${ }^{[19]}$ in a study of 78 participants with 33 healthy participants and 45 patients with RA, reported significant higher clinical periodontal parameters in the RA group than the control group. The present study aims to evaluate the periodontal status and its association with sociodemographic and clinical factors in patients with RA.

\section{Materials and Methods}

\section{Study Population}

A total of 51 patients with RA ( 6 males, 45 females; mean age $49.75 \pm 9.79$ years; range 25 to 69 years) at the outpatient clinic was involved in this study between September and October 2019. Patients who were diagnosed as having RA using the 1987 American College of Rheumatology (ACR) classification criteria ${ }^{[20]}$ were enrolled in this study if they had at least 20 teeth present, excluding the third molars. The exclusion criteria were as follows: (i) pregnancy or lactating, (ii) any systemic conditions that could affect the progression of periodontal disease, such as uncontrolled $D M$, severe hypertension, severe renal insufficiency or malignancies, (iii) a history of taking antibiotics during the previous three months, (iv) receiving periodontal treatment recently $(<1$ year).

The study protocol was approved by the Faculty Ethics Committee (decision number-date: 10840098-60.4.01.01E.59442-2019). Written informed consent was obtained from each patient. This study was conducted in accordance with the principles of the Declaration of Helsinki.

\section{Clinical Measurements}

Sociodemographic characteristics, such as age, sex, weight, height, education, marital and working status, smoking and alcohol habits, were provided by the patient. Body mass index $\left(\mathrm{kg} / \mathrm{m}^{2}\right)$ was calculated using a patient's height and weight. Disease duration and current use of anti-rheumatic medications were recorded. Blood samples were analyzed for Erythrocyte sedimentation rate (ESR), serum C- reactive protein (CRP), serum rheumatoid factor (RF) and anti-cyclic citrullinated peptide antibody (anti-CCP). Disease activity score 28 (DAS28) was calculated based on the number of joints tender to touch, the number of swollen joints, CRP and the patient's general health ${ }^{[21]}$. Physical examinations and DAS28 score calculations were performed by a welltrained, experienced researcher (AR).

\section{Periodontal Examination}

Full-mouth examinations were performed by one experienced periodontist (TD). Four periodontal variables, including Gingival index $(\mathrm{Gl})$, Plaque index (PI), Pocket probing depth (PPD) and Clinical attachment level (CAL), were evaluated. The PI and GI were used to evaluate oral hygiene and 
gingival health status, respectively ${ }^{[12,22]}$. The periodontist examined gingival recession, PPD, and CAL of each tooth present, in millimetre $(\mathrm{mm})$, at six sites per tooth, using a manual periodontal probe and the readings were recorded to the nearest $1 \mathrm{~mm}$. Gingival recession was defined as the displacement of the gingival margin apical to the cementoenamel junction (CEJ). PPD was defined as the distance from the free gingival margin to the bottom of the sulcus or periodontal pocket. CAL expressed as the distance in millimeters from the CEJ to the bottom of the sulcus or periodontal pocket and was calculated as the sum of PPD and gingival recession measurements. All teeth present in the mouth were examined for reducing a chance of underestimating PD cases compared to partial mouth records in both prevalence and severity of PD.

The periodontal status was classified according to the Centers for Disease Control (CDC)-American Academy of Periodontology (AAP) clinical case definitions. The patients who had $\geq 2$ interproximal sites with $C A L \geq 3 \mathrm{~mm}$, and $\geq 2$ interproximal sites with PPD $\geq 4 \mathrm{~mm}$ (not on the same tooth) or one site with PPD $\geq 5 \mathrm{~mm}$ was categorized as mild periodontitis. Moderate periodontitis was accepted as $\geq 2$ interproximal sites with CAL $\geq 4 \mathrm{~mm}$ (not on the same tooth), or $\geq 2$ interproximal sites with PPD $\geq 5 \mathrm{~mm}$ (not on the same tooth) and severe periodontitis was admitted as $\geq 2$ interproximal sites with CAL $\geq 6 \mathrm{~mm}$ (not on the same tooth) and $\geq 1$ interproximal site with PPD $\geq 5 \mathrm{~mm}^{[23]}$. The number of teeth present was also recorded.

\section{Statistical Analysis}

Data were analyzed using the IBM-SPSS for Windows version 23.0 software package (IBM Corp. Released 2015. IBM SPSS Statistics for Windows, Version 23.0. Armonk, NY: IBM Corp.). The Shapiro-Wilk test was used to evaluate the normality of data. Frequency, percentage, mean and standard deviation, median, minimum and maximum were used for descriptive statistics. For two-group comparisons (mild vs. moderate), we used the Chi-square test, Fisher's exact test for categorical variables, the Independent Sample t-test for continuous data if the normal distribution of variables existed, and the Mann-Whitney $U$ test in other cases. A pvalue of $<0.05$ was considered statistically significant.

\section{Results}

This study included 51 patients ( 45 females and six males) with a mean age of $49.75 \pm 9.79$ years. Sociodemographic, periodontal and clinical characteristics of patients with RA are described in Table 1. Forty-five patients (88.2\%) were female. Thirty-three patients (64.7\%) had a primary school
Table 1. Sociodemographic, periodontal and clinical characteristics of patients with rheumatoid arthritis

Variables $\quad n=51$

Gender, female, n (\%)

45 (88.2)

Age, years (mean \pm SD)

$49.75 \pm 9.79$

BMl, $\mathrm{kg} / \mathrm{m}^{2}$ (mean \pm SD)

Educational level, $\mathrm{n}(\%)$

Primary school

$29.31 \pm 4.61$

Secondary school

$33(64.7)$

High school

$9(17.6)$

9 (17.6)

Marital status, n (\%)

Married

47 (92.2)

Single

4 (7.8)

Occupation, n (\%)

Housekeeping

$36(70.6)$

Employee

$10(19.6)$

Others

$5(9.8)$

Smoking, n (\%)

Non-smoker

24 (47.1)

Current or ex-smoker

27 (52.9)

Alcohol consumption, $\mathrm{n}$ (\%)

Periodontal status, median [min-max]

Remaining teeth

24 [20-28]

Pocket probing depth, $\mathrm{mm}$

Clinical attachment level, $\mathrm{mm}$

Plaque Index, $\mathrm{mm}$

Gingival index, $\mathrm{mm}$

1.96 [1.10-4]

$2.22[1.10-4.61]$

$1.50[0-3]$

$0.40[0.03-1]$

Rheumatoid arthritis status

Duration, years (mean $\pm S D$ )

$10.59 \pm 6.37$

RF positive, $n$ (\%)

$32(62.7)$

Anti-CCP positive, $\mathrm{n}(\%)$

27 (52.9)

$\mathrm{ESR}, \mathrm{mm} / \mathrm{h}$ (mean $\pm \mathrm{SD})$

$22.32 \pm 15.71$

$\mathrm{CRP}, \mathrm{mg} / \mathrm{L}$ (mean $\pm \mathrm{SD})$

$1.12 \pm 2.84$

DAS28 (mean \pm SD)

$2.95 \pm 0.94$

18 (35.3)

$14(27.5)$

Lox disease activity ( $>2.6 \mathrm{y} \leq 3.2)$

$19(37.3)$

High disease activity $(>5.1)$

Current treatment, $\mathrm{n}$ (\%)

Prednisolone

Methotrexate

Leflunomide

Hydroxychloroquine

Sulfasalazine

Biologic or Jak inhibitors

Folic acid

Mono-DMARDs

Combined DMARDs

Comorbidities, n (\%)

Secondary Sjögren's syndrome 19 (37.3)

Diabetes mellitus

Hypertension

Thyroid disease

4 (7.8)

$12(23.5)$

$5(9.8)$

Coronary artery disease

$2(3.9)$

Osteoporosis

$5(9.8)$

n: number of subjects; Anti-CCP: anti-cyclic citrullinated peptide; CRP: C-reactive protein; DAS28: Disease Activity Score28; DMARD: diseasemodifying anti- rheumatic drugs; ESR: erythrocyte sedimentation rate; RF: rheumatoid factor; SD: standard deviation; $\mathrm{mm}$ : millimeter. 
education level. Forty-seven percent had never smoked. Among common co-morbidities, there was sSS in 19 (37.3\%) cases, hypertension in twelve (23.5\%), DM in four $(7.8 \%)$, thyroid disease in five $(9.8 \%)$, coronary artery disease in two (3.9\%) and osteoporosis in five (9.8\%) (Table 1). In periodontal examination, median [min-max] CAL was 2.22 [1.10-4.61] $\mathrm{mm}$. The level of gingival inflammation was low (median [min-max] Gl=0.40 [0.03-1]) and oral hygiene was fair (median [min-max] Pl=1.50 [0-3]) (Table 1). No patients underwent periodontal treatment during the study period.

The duration range of RA was 1-27 years (mean 10.59 \pm 6.37 ). RF was positive in $62.7 \%$ of the cases, and anti-CCP was positive in $52.9 \%$ of the patients. The mean DAS28 score was $2.95 \pm 0.94$, in which their disease activity was classified as remission, low and moderate according to DAS28 calculation of $35.3 \%, 27.5 \%$, and $37.3 \%$, respectively. There were no patients with high disease activity (DAS28>5.1). All patients with RA were treated with one or more antirheumatic medications, $70.6 \%$ used methotrexate, $15.7 \%$ used prednisolone, and $70.6 \%$ used mono-disease-modifying antirheumatic drugs (Table 1).
All patients with RA were detected marked PD. The periodontal status of patients is classified as mild and moderate PD, according to the CDC-AAP clinical case definitions. Sociodemographic characteristics, disease characteristics, and periodontal parameters according to the periodontal status of patients are shown in Table 2.

Patients with moderate PD significantly had higher age and DAS 28 score, PI, PPD and CAL levels $(p=0.007, p<0.001$, $p=0.012, p=0.025, p=0.001$, respectively). Patients with mild PD had significantly never smoked and had less diagnosis of $s S S(p=0.009, p=0.010)$. The higher number of teeth was significantly detected in patients with mild PD mouth ( $p=0.04$ ) (Table 2 ).

\section{Discussion}

This study evaluated the periodontal status in patients with RA and revealed its relationship with sociodemographic and clinical factors. We found that periodontal health was affected in all patients with RA. This finding was in line with those of a systematic review in which a high prevalence of periodontitis (15.5-100\%) was reported in patients with RA, compared with controls $(10-82.1 \%)^{[14]}$. Although some fea-

Table 2. Sociodemographic characteristics, disease parameters and periodontal parameters according to periodontal status

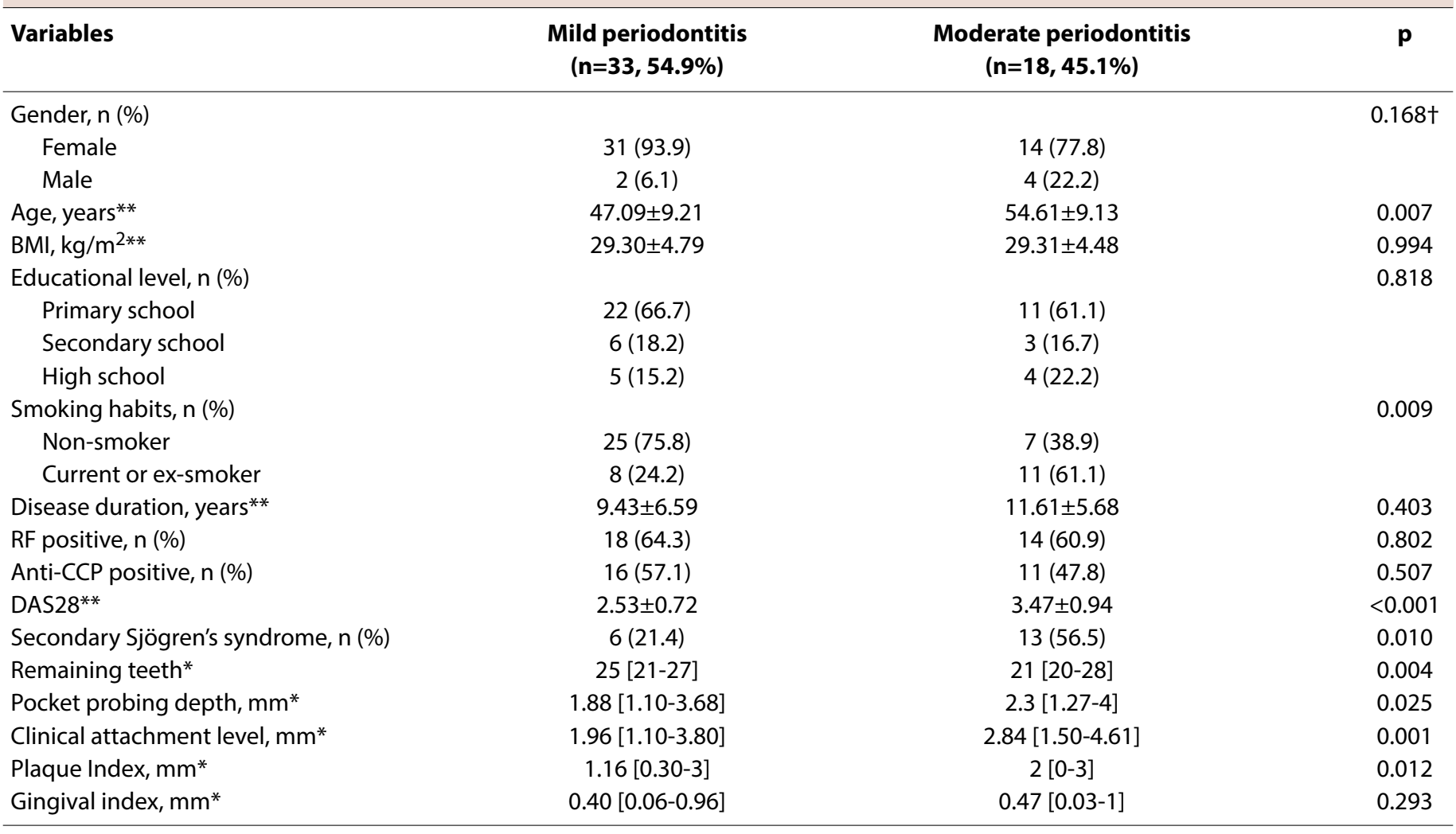

$\mathrm{p}$-values are based on the Independent t-test or Mann-Whitney $\mathrm{U}$ test for continuous data or $\mathrm{X}^{2}$ test for frequency data; + Fisher test; ${ }^{*}$ median [min-max]; **(mean \pm SD). 
tures of the inflammatory response appear to be similar in both diseases, the causality in the pathogenesis between them is still unclear.

In this study, the severity of PD was classified according to the CDC-AAP case definitions ${ }^{[23]}$. We found mild and moderate PD in $54.9 \%$ and $45.1 \%$ of patients with RA, respectively. The same criteria, which use CAL and PPD to detect PD, have also been used in previous studies ${ }^{[14-17}$, 19]. Several factors, such as smoking, poor oral hygiene, the presence of sSS, anti-rheumatic medications, aging, heredity, disease activity of RA and impaired hand functions required for oral hygiene practices, have been supposed to development of $P D^{[5,14-17,19,24]}$. These risk factors, modifiable and non-modifiable, contribute toward the clinical significance of PD.

In the present study, sociodemographic characteristics, clinical and periodontal parameters were compared between groups of patients with mild and moderate PD. The results showed that only age, smoking habit, DAS28 score, sSS, Pi, PPD and CAL measurements showed a statistically significant difference between the two groups.

RA displays a striking imbalance between the genders, with females representing the majority of cases $^{[1,25,26]}$. Females also slightly have worse levels of disease activity and function compared with men ${ }^{[26]}$. Similarly, previous studies reported a significantly increased risk and severity of PD in patients with RA, especially females ${ }^{[14,24]}$. In this study, $88.2 \%$ of the patients with RA were female. However, no difference was found between genders concerning PD severity because of the relatively small sample size of males.

The risk of PD increases with age and is highest in adults aged more than 65 years ${ }^{[23]}$. Age is also an important confounding factor in the relationship between RA and PD or tooth loss ${ }^{[27]}$. Several factors, including older age, smoking, low socioeconomic status, and comorbidities, such as DM, were already found to be associated with tooth loss. However, RA was also reported as an independent factor associated with tooth loss in younger adults ${ }^{[27,28]}$. Therefore, it was no surprise that the study population in moderate PD group had a significantly higher mean age with a higher number of tooth loss. The present study sug $\neg$ gests that increased PD severity in older patients with RA might progress easily to tooth loss.

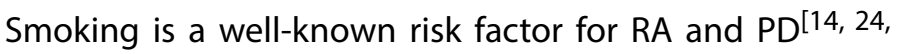
$29,30]$. Smoking increases the risk of developing seropositive, but not seronegative $\mathrm{RA}^{[30]}$. It also increases the risk of developing ACPA in patients with RA who carry shared epitope alleles and is a risk factor for RA severity ${ }^{[31]}$. In this study, nearly half of the patients with RA were non-smokers. However, study results showed that former and current smokers had a higher severity of PD than non-smokers similar to previous study results $[27,29-31]$.

The association between PD and seropositive RA has been already reported ${ }^{[30,31]}$. Periodontitis-associated pathogens, such as Porphyromonas Gingivalis and Aggregatibacter Actinomycetemcomitans, induce citrullination as explaining in RA pathogenesis. It was found a positive correlation between the serum concentration of ACPA and anti- Porphyromonas gingivalis immunoglobulin $G$ level in patients with $\mathrm{RA}^{[32]}$. These results suggest that Porphyromonas gingivalis play a role in the citrullination of peptides involved in the mechanism of autoimmunity. On the other hand, it was found that the risk of RA development does not change after the antibiotherapy for $P D^{[16]}$. In this study, we did not find any association between PD severity and seropositivity of RA, but it may be possible to demonstrate this association with a larger patient population.

Although no relationship was found between the disease duration of RA and the development of PD, long-standing active RA has been accepted as a causative factor of $\mathrm{PD}^{[33]}$. Furthermore, disease activity was reported to be positively correlated with PD severity ${ }^{[14,29]}$. Smit et al. ${ }^{[34]}$ reported that RA patients with severe PD had higher DAS28 scores than those with no or moderate PD. Also, Al-Katma et al. ${ }^{[35]}$ showed that treatment of PD can decrease the severity of RA activity and can cause a reduction in serum tumor necrosis factor-alpha level. Similarly, we found that patients with moderate PD had higher disease activity than the patients with mild PD. Even if our patient group had a low mean DAS28 score, the long mean disease duration (10.59 \pm 6.37 years) might explain the reason for such a high prevalence of PD.

Oral hygiene is a strong risk indicator for PD in not only patients with RA but also in the general population. Functional upper limb disabilities in patients with RA might contribute to poor manual dexterity with the toothbrush and a lower oral hygiene status ${ }^{[36]}$. Pischon et al. ${ }^{[37]}$ declared that poor oral hygiene might be partially accounted for the association between RA and PD. In this study, although the average oral hygiene level of the patients was fair, it seemed to play an important role in developing PD in our patient group.

The absence of normal saliva production impedes to keep the mouth lubricated. The relationship between PD and primary Sjögren's syndrome (pSS) has been evaluated in many studies and it has been noted that the prevalence of 
PD in pSS patients increases due to decreased saliva flow and consequent higher dental plaque index ${ }^{[38,39]}$. This evidence may suggest that SSS may play an additional aggravating role in the deteriorating oral health of patients with RA. In our study group, moderate severity of PD was found in the subgroup of patients with sSS.

The present study has some limitations. First, the small number of subjects presenting to a university hospital who were analyzed in a cross-sectional study in design is one of the limitations of of our study. Second, we have no control group for comparing potential risk factors of PD. Third, we enrolled only cases that had at least 20 teeth, serious PD cases with less number of teeth might have been overlooked. Four, data concerned daily oral hygiene habits and dental visits that affect the development of PD were not asked. Five, the effects of functional ability of the hand with upper limb function and quality of life in patients with RA on the severity of PD were not evaluated. Lastly, we did not analyze the causal mechanism between RA and PD and observed the treatment effects of PD on RA disease activity.

\section{Conclusion}

In the present study, we found such a high prevalence of PD in patients with RA. Aging, impaired oral hygiene, previous and current smoking, sSS and high disease activity were the contributing factors for increasing the severity of PD in our study population. We identified a serious need to pay particular attention to oral health in patients with RA and refer people for dental and periodontal evaluation and treatment. By this means, the clinical course of RA may be affected and the functional status of the patients may be positively changed. Future studies are needed to determine better whether if efforts to prevent periodontal disease might also help prevent RA.

Ethics Committee Approval: The Ethics Committee of Medipol University provided the ethics committee approval for this study (10840098-604.01.01-E.59442, 31.10.2019).

Peer-review: Externally peer-reviewed.

Authorship Contributions: Concept: S.T.; Design: S.T., A.R.,T.D.; Data Collection or Processing: A.R., T.D.; Analysis or Interpretation: S.T., D.Ö., A.Ü., T.D.; Literature Search: S.T., A.Ü., D.Ö.; Writing: S.T.

Conflict of Interest: None declared.

Financial Disclosure: The authors declared that this study received no financial support.

\section{References}

1. Krasselt M, Baerwald C. Sex, Symptom Severity, and Quality of Life in Rheumatology. Clin Rev Allergy Immunol 2019;56:346-
61. [CrossRef]

2. Verstappen SMM. The impact of socio-economic status in rheumatoid arthritis. Rheumatology (Oxford) 2017;56:1051-2.

3. Gualtierotti R, Marzano AV, Spadari F, Cugno M. Main Oral Manifestations in Immune-Mediated and Inflammatory Rheumatic Diseases. J Clin Med 2018;8:21. [CrossRef]

4. Potempa J, Mydel P, Koziel J. The case for periodontitis in the pathogenesis of rheumatoid arthritis. Nat Rev Rheumatol 2017;13:606-20. [CrossRef]

5. Li R, Tian C, Postlethwaite A, Jiao Y, Garcia-Godoy F, Pattanaik $D$, et al. Rheumatoid arthritis and periodontal disease: What are the similarities and differences? Int J Rheum Dis 2017;20:1887-901. [CrossRef]

6. Cheng Z, Meade J, Mankia K, Emery P, Devine DA. Periodontal disease and periodontal bacteria as triggers for rheumatoid arthritis. Best Pract Res Clin Rheumatol 2017;31:19-30. [CrossRef]

7. Gómez-Bañuelos E, Mukherjee A, Darrah E, Andrade F. Rheumatoid Arthritis-Associated Mechanisms of Porphyromonas gingivalis and Aggregatibacter actinomycetemcomitans. J Clin Med 2019;8:1309. [CrossRef]

8. Lundberg K, Wegner N, Yucel-Lindberg T, Venables PJ. Periodontitis in RA-the citrullinated enolase connection. Nat Rev Rheumatol 2010;6:727-30. [CrossRef]

9. Richards D. Oral diseases affect some 3.9 billion people. Evid Based Dent 2013;14:35. [CrossRef]

10. CDC researchers find close to half of American adults have periodontitis. J Can Dent Assoc 2012;78:c136.

11. Ebersole JL, Dawson D 3rd, Emecen-Huja P, Nagarajan R, Howard K, Grady ME, et al. The periodontal war: microbes and immunity. Periodontol 2000 2017;75:52-115. [CrossRef]

12. Loe H, Silness J. Periodontal Disease in Pregnancy. I. Prevalence and Severity. Acta Odontol Scand 1963;21:533-51.

13. Whitmore SE, Lamont RJ. Oral bacteria and cancer. PLoS Pathog 2014;10:e1003933. [CrossRef]

14. Tang Q, Fu H, Qin B, Hu Z, Liu Y, Liang Y, et al. A Possible Link Between Rheumatoid Arthritis and Periodontitis: A Systematic Review and Meta-analysis. Int J Periodontics Restorative Dent 2017;37:79-86. [CrossRef]

15. Arkema EV, Karlson EW, Costenbader KH. A prospective study of periodontal disease and risk of rheumatoid arthritis. J Rheumatol 2010;37:1800-4. [CrossRef]

16. Chen HH, Huang N, Chen YM, Chen TJ, Chou P, Lee YL, et al. Association between a history of periodontitis and the risk of rheumatoid arthritis: a nationwide, population-based, casecontrol study. Ann Rheum Dis 2013;72:1206-11. [CrossRef]

17. Demmer RT, Molitor JA, Jacobs DR Jr, Michalowicz BS. Periodontal disease, tooth loss and incident rheumatoid arthritis: results from the First National Health and Nutrition Examination Survey and its epidemiological follow-up study. J Clin Periodontol 2011;38:998-1006. [CrossRef]

18. Tuncer T, Gilgil E, Kaçar C, Kurtaiş Y, Kutlay Ş, Bütün B, et al. Prevalence of Rheumatoid Arthritis and Spondyloarthritis in Turkey: A Nationwide Study. Arch Rheumatol 2017;33:128-36. 19. Ay ZY, Bozkurt FY, Akkuş S. Romatoid artrit hastalarının peri- 
odontal sağlık durumunun değerlendirilmesi. S.D.Ü. Tıp Fak Derg 2007;14:26-9.

20. Arnett FC, Edworthy SM, Bloch DA, McShane DJ, Fries JF, Cooper NS, et al. The American Rheumatism Association 1987 revised criteria for the classification of rheumatoid arthritis. Arthritis Rheum 1988;31:315-24. [CrossRef]

21. Prevoo ML, van 't Hof MA, Kuper $H H$, van Leeuwen $M A$, van de Putte LB, van Riel PL. Modified disease activity scores that include twenty-eight-joint counts. Development and validation in a prospective longitudinal study of patients with rheumatoid arthritis. Arthritis Rheum 1995;38:44-8. [CrossRef]

22. Silness J, Loe H. Periodontal Disease in Pregnancy. II. Correlation Between Oral Hygiene and Periodontal Condtion. Acta Odontol Scand 1964;22:121-35. [CrossRef]

23. Eke PI, Page RC, Wei L, Thornton-Evans G, Genco RJ. Update of the case definitions for population-based surveillance of periodontitis. J Periodontol 2012;83:1449-54. [CrossRef]

24. Araújo VM, Melo IM, Lima V. Relationship between Periodontitis and Rheumatoid Arthritis: Review of the Literature. Mediators Inflamm 2015;2015:259074. [CrossRef]

25. Bax M, van Heemst J, Huizinga TW, Toes RE. Genetics of rheumatoid arthritis: what have we learned? Immunogenetics 2011;63:459-66. [CrossRef]

26. Tengstrand $B$, Ahlmén $M$, Hafström I. The influence of sex on rheumatoid arthritis: a prospective study of onset and outcome after 2 years. J Rheumatol 2004;31:214-22.

27. Kim JW, Park JB, Yim HW, Lee J, Kwok SK, Ju JH, et al. Rheumatoid arthritis is associated with early tooth loss: results from Korea National Health and Nutrition Examination Survey $V$ to VI. Korean J Intern Med 2019;34:1381-91. [CrossRef]

28. Musacchio E, Perissinotto E, Binotto P, Sartori L, Silva-Netto F, Zambon $S$, et al. Tooth loss in the elderly and its association with nutritional status, socio-economic and lifestyle factors. Acta Odontol Scand 2007;65:78-86. [CrossRef]

29. Eke PI, Wei L, Thornton-Evans GO, Borrell LN, BorgnakkeWS, Dye $B$, et al. Risk Indicators for Periodontitis in US Adults: NHANES 2009 to 2012. J Periodontol 2016;87:1174-85. [CrossRef]

30. Stolt P, Bengtsson C, Nordmark B, Lindblad S, Lundberg I,
Klareskog L, et al; EIRA study group. Quantification of the influence of cigarette smoking on rheumatoid arthritis: results from a population based case-control study, using incident cases. Ann Rheum Dis 2003;62:835-41. [CrossRef]

31. Linn-Rasker SP, van der Helm-van Mil AH, van Gaalen FA, Kloppenburg M, de Vries RR, le Cessie S, et al. Smoking is a risk factor for anti-CCP antibodies only in rheumatoid arthritis patients who carry HLA-DRB1 shared epitope alleles. Ann Rheum Dis 2006;65:366-71. [CrossRef]

32. Hitchon CA, Chandad F, Ferucci ED, Willemze A, loan-Facsinay $A$, van der Woude $D$, et al. Antibodies to porphyromonas gingivalis are associated with anticitrullinated protein antibodies in patients with rheumatoid arthritis and their relatives. J Rheumatol 2010;37:1105-12. [CrossRef]

33. Kässer UR, Gleissner C, Dehne F, Michel A, Willershausen-Zönnchen $B$, Bolten WW. Risk for periodontal disease in patients with longstanding rheumatoid arthritis. Arthritis Rheum 1997;40(12):2248-51. [CrossRef]

34. de Smit M, Westra J, Vissink A, Doornbos-van der Meer B, Brouwer $E$, van Winkelhoff AJ. Periodontitis in established rheumatoid arthritis patients: a cross-sectional clinical, microbiological and serological study. Arthritis Res Ther 2012;14:R222. [CrossRef]

35. Al-Katma MK, Bissada NF, Bordeaux JM, Sue J, Askari AD. Control of periodontal infection reduces the severity of active rheumatoid arthritis. J Clin Rheumatol 2007;13:134-7. [CrossRef]

36. Reichert S, Machulla HK, Fuchs C, John V, Schaller HG, Stein J. Is there a relationship between juvenile idiopathic arthritis and periodontitis? J Clin Periodontol 2006;33:317-23. [CrossRef]

37. Pischon N, Pischon T, Kröger J, Gülmez E, Kleber BM, Bernimoulin JP, et al. Association among rheumatoid arthritis, oral hygiene, and periodontitis. J Periodontol 2008;79:979-86.

38. Pers JO, d'Arbonneau F, Devauchelle-Pensec V, Saraux A, Pennec $Y L$, Youinou P. Is periodontal disease mediated by salivary BAFF in Sjögren's syndrome? Arthritis Rheum 2005;52:2411-4.

39. Boutsi EA, Paikos S, Dafni UG, Moutsopoulos HM, Skopouli FN. Dental and periodontal status of Sjögren's syndrome. J Clin Periodontol 2000;27:231-5. [CrossRef] 